Vocational Identity Development among Unaccompanied Refugee Minors Brit Oppedal, Norwegian Institute of Public Health Eugene Guribye, Agder Research Jane Kroger, University of Troms $\varnothing$; Western Washington University

Author Note: Brit Oppedal, Department of Child Development and Mental Health, Norwegian Institute of Public Health; Eugene Guribye, Welfare Department, Agder Research; Jane Kroger, Psychology Department, University of Tromsoe

Correspondence concerning this article should be addressed to Brit Oppedal, Norwegian Institute of Public Health, PHOK, P.O.Box 4404, Nydalen, N-0403 Oslo, Norway. E-mail: brit.oppedal@fhi.no 


\begin{abstract}
This study examined educational aspirations and vocational identity formation among unaccompanied refugees in Norway. In Phase 1 we employed questionnaire data from 918 unaccompanied refugees to investigate the effects of demographic information, pre-migration trauma, mental health and acculturation-related factors on their educational aspirations. In Phase 2, data from Identity Status Interviews (ISI) with 29 participants was analyzed to obtain information about vocational identity status distribution and to examine core themes and contextual factors underlying their vocational choices. The findings from Phase 1 showed that none of the theoretically and empirically based included variables had a significant effect on their aspirations. Moreover, the overall regression model was non-significant. We discussed these findings in relation to the strong motivation among unaccompanied minors to create better lives for themselves than they could have in the countries they fled from, irrespective of their traumatic experiences and mental health problems. In Phase 2 the most important themes emerging from the ISIs revolved around age, time, and economics. The remedial education to bridge the pre-flight gap in formal education meant that the unaccompanied refugee youth entered upper secondary school at substantially older ages than their classmates. Their older ages then led them to prioritize economic considerations in making vocational choices, since the support from the Child Welfare Services is discontinued when they reach the age of majority. Consequently, most of them chose short vocational paths toward earning a living, rather than complex roads that led to the realization of their own long-term aspirations. This may have limited the social mobility of unaccompanied refugees.
\end{abstract}




\section{Vocational Identity Development among Unaccompanied Refugee Minors}

The steady increase in minor refugees and asylum-seekers arriving in Europe, with an historic peak in 2015, is taking place at the same time as these countries are struggling with economic problems and an alarmingly high proportion of, particularly youth, unemployment. Young people are highly affected during periods of economic crisis. Not only are they the first targets for job cuts, but in addition, their transition from school to the job market becomes almost impossible, with associated sentiments of hopelessness for the future and high school drop-out rates (Choudhry, Marelli, \& Signorelli, 2012). There is a widespread concern that the so-called Youth Not in Education, Employment or Training (NEET) presents a major risk for social exclusion and marginalization, with the prospect of social revolt seen in France in 2005 (Christafis, 2015), or even radicalization (European Commission, 2015). Youth with migrant backgrounds, health problems, and/or lower educational attainments are more likely to become NEETs than other youths from host cultural contexts. Thus, social inclusion and integration of young people with a migrant background, including newlyarrived migrants and refugees, is a key aim of the EU. Education is the main vehicle to reach this goal (European Commission, 2015).

However, research suggests that there is a need to understand the heterogeneity and varied situations and difficulties that these youth face (Yates \& Payne, 2006). As such, unaccompanied minor asylum-seekers, i.e. children who migrate without the company of an adult caretaker to apply for asylum in a foreign country, constitute a group of youth with a particularly challenging situation. They are fleeing war, violence, and poverty in their home countries with the associated absence of opportunities for a decent life (Hopkins \& Hill, 2008). They are the most vulnerable of all immigrant groups regarding prevalence of mental health problems, and yet they are ambitious with a strong will to adapt and succeed in the 
countries that grant them asylum (Bean, Derluyn, Eurelings-Bontekoe, Broekaert, \& Spinhoven, 2007; Kohli, 2007; Oppedal \& Idsoe, 2015). Their complex individual histories have often deprived them of developmentally supportive experiences within the safe haven of the family, the learning environment of the school, or with continuous peer relations, thereby impeding their social, emotional, and cognitive development (Baltes, 1987). Importantly, the frequent break-down of educational institutions in the countries of origin, combined with often long travels to reach the countries of asylum, contribute to a serious lack of formal education among unaccompanied minors. Their re-entry into the educational system after resettlement therefore typically involves catching up with the curriculum of lower grade levels before they enter ordinary education, which for a majority of them implies secondary schooling. At this transition, they face a series of choices with important implications for their futures, such as entering a vocational job-qualifying track, or a theoretical track necessary for later admission into colleges and universities.

The majority of unaccompanied minors seeking asylum in Europe are between 15 and 18 years old, where forming an identity within sexual, ideological, and vocational domains is one of the major developmental tasks of adolescence (Kroger, Martinussen, \& Marcia, 2010; Marcia, 1980). Many studies have focused on identity development during adolescence (Kroger et al., 2010; Liebkind, 1993; Marcia, 1980; Meeus, Iedema, Helsen, \& Vollebergh, 1999; Phinney, 1989b); however, when refugees and other immigrant youth are concerned, the focus has mostly been on the domain of ethnic identity formation (Mossakowski, 2003; Phinney, 1989b; Tartakovsky, 2009; Umaña-Taylor \& Updegraff, 2007). Still, making decisions about education and vocation are important aspects of acculturation for refugee youths as they gain insights into the educational institutions and the demands of the labor market in the host country. Furthermore, education is one of society's major tools in social mobility and social integration. Considering the individual and future societal importance of 
the choices that they make, it is essential to get information about the barriers and resources that are available to them in this process and what support they need to succeed educationally in unfamiliar cultural settings, based on their own stories. Knowledge about how unaccompanied minor asylum-seekers negotiate vocational possibilities in their new contexts as part of the identity formation process could provide such insights. Yet to our knowledge, no studies have investigated these questions.

With this background, the overall aim of the present study is to examine vocational identity developmental processes underlying the educational choices of unaccompanied minors who have received asylum and residence in Norway (Marcia, 1999). In other words, we seek to better understand if and how the extraordinary developmental context of these youths affects normative youth developmental processes. This knowledge can inform theory as well as policy and practices. Since the participants of this study have been granted residence and consequently are no longer asylum-seekers and many have reached the age of majority, we refer to them as unaccompanied refugees. We still use the terms unaccompanied minors or unaccompanied minor asylum-seekers to refer to this population in general.

\section{Educational Aspirations in Refugee Context}

Studies have shown that immigrant and refugee background youths have high educational aspirations (Salikutluk, 2016; Shakya et al., 2010; Stevenson \& Willott, 2007), and females more so than males (Wei-Cheng \& Lynette Heim, 2000). Factors associated with the refugee experience, such as pre-migration traumatic experiences and subsequent symptoms of post-traumatic stress disorder (PTSD) and depression may, however, reduce aspirations (Nadeem \& Ringle, 2016). Many youths, however, view higher education as a route out of poverty and discrimination, and as a proactive response to overcome premigration experiences of forced migration and educational disruption (Shakya et al., 2010; 
Stevenson \& Willott, 2007; Teney, Devleeshouwer, \& Hanquinet, 2013). Acculturation related resources such as majority language preference and fluency, as well as a strong orientation towards the majority culture also predict educational aspirations (Flores, Navarro, \& Dewitz, 2008; Fuligni, Witkow, \& Garcia, 2005; Ong, Phinney, \& Dennis, 2006; StHilaire, 2002). To our knowledge, this scholarly literature on educational aspirations of immigrant and refugee youth does not include studies that examine predictors of the vocational aspirations of unaccompanied minors. Therefore, as a first phase of the study, we use quantitative data from a population based sample of unaccompanied refugees to examine level of educational aspiration and the extent to which pre-migration trauma, mental health, and acculturation related factors predict educational aspirations. This aim is to examine whether findings from previous studies might be generalized to the unaccompanied refugee context.

The second phase employs data from semi-structured interviews with 29 of the participants to explore deliberations and concerns underlying the identity-defining decisions these youths make about education and work, and the barriers and opportunities they encounter in the process.

The mixed-method approach to obtain information about educational aspirations and vocational identity development may provide different perspectives and triangulation of data about social mobility resources and barriers among undereducated young unaccompanied refugees. The findings may also inform strategic policy planning of intervention to promote economic independence and integration for these youths.

\section{Identity Development in Socio-cultural Context}

During adolescence, individuals are generally faced with the task of forming an identity and making decisions about roles and values related to education, occupation, 


\section{MINORS}

ideological values, gender, peer relations, and, for ethnic minorities in particular, cultural roles and values (Erikson, 1968; Marcia, Waterman, Matteson, Archer, \& Orlofsky, 1993; Phinney, 1989b). Even if conceptual perspectives on the identity formation process may vary among scholars, most, following the seminal work of Marcia (1966), agree that two different psychological processes are involved: exploration of alternative roles or values that are available within a given context, and commitment to those roles or values that are considered most meaningful to the individual (Bosma \& Kunnen, 2001; Grotevant, 1987; Kroger et al., 2010; Meeus et al., 1999; Phinney, 1989a). Based on the extent to which the adolescent engages in the processes of exploration and commitment, four identity statuses have been outlined by Marcia (1966; Marcia et al., 1993): An achieved identity status reflects commitment to a social role after a period of extensive exploration. A moratorium status describes individuals who are actively involved in exploring different identity-defining possibilities, but have not yet made firm commitments. Individuals who have committed to a role or set of values with little, if any, exploration of alternatives as a result of identification with or expectations from significant others, are described as being in a foreclosed identity status. The diffusion status is ascribed to someone who has neither explored nor committed to a personally meaningful role or set of values, and appears quite disinterested in doing so (Kroger \& Marcia, 2011). Identity statuses are preferably assessed through the Identity Status Interview, ISI (Marcia et al., 1993); however various paper and pencil measures have also been constructed, e.g. (Crocetti, Rubini, \& Meeus, 2008; Kroger \& Marcia, 2011; Phinney, 1992).

The arena of educational and vocational identity development, included in Marcia's Identity Status Interview (ISI), has commonly been used independently to understand the process of vocational decision-making in the adolescent identity formation process. Skorikov and Vondracek (2011) summarized over 50 years of research probing the structure, functions, 


\section{MINORS}

and development of vocational identity, noting that vocational identity development during adolescence may be quite variable; however, during high school many adolescents begin seriously to question and reconsider work and vocational attitudes, beliefs, and values held by significant others and friends (Skorikov \& Vondracek, 2011). Adolescents and young adults who approach the task of finding a vocation with a sense of agency are more likely to engage in identity exploration and to make flexible vocational commitments and are less likely to be conforming or avoiding vocational choices (Schwartz, Côté, \& Arnett, 2005). Postponing vocational commitments without engaging in vocational exploration has been described as “floundering," likely associated with identity diffusion. Developing a sense of vocational direction and a tentative vocational identity through selecting a course of study and transitioning from school to work is one of the key developmental tasks of late adolescence (Skorikov \& Vondracek, 2011).

Vocational identity formation processes are embedded in and interact dynamically with youths' close relationships, especially with parents and peers (Bosma \& Kunnen, 2001; Doumen et al., 2012; Kroger \& Marcia, 2011; Meeus, Oosterwegel, \& Vollebergh, 2002; Samuolis, Layburn, \& Schiaffino, 2001; van Doeselaar, Meeus, Koot, \& Branje, 2016; Wiley \& Berman, 2012). While the majority of unaccompanied refugees do not have parents or other family members available for advice and support in their identity exploration processes, they report having good quality relationships with immigrant and non-immigrant friends (Oppedal \& Idsoe, 2015) who might provide information and feedback to facilitate their vocational choices. Still, we do not know if the unaccompanied refugees perceive their friends as important, supportive resources in their decisions about educational and vocational pathways, or if the majority culture friends serve as cultural brokers in the understanding of the educational system of the receiving society. The role of social networks and the extent to which educational choices are based on preceding stages of exploration and commitment 


\section{MINORS}

represent important gaps in current knowledge about vocational identity formation among unaccompanied refugees. An important aim of the present study is, therefore, to address these questions.

\section{Variation in Vocational Identity Formation by Age and Institutional Factors}

While associations between identity development and age have been shown during adolescence and young adulthood, several social, cultural, and institutional factors also influence one's degree of exploration and commitment (Baumeister \& Muraven, 1996; Baumeister, Shapiro, \& Tice, 1985; Kalakoski \& Nurmi, 1998; Kroger et al., 2010; Munro \& Adams, 1977; Nurmi, Poole, \& Kalakoski, 1996; Yoder, 2000). Baumeister's (1986) historical analysis of identity development among youth revealed that different societies, or the same society at different historical times, provide different levels of choice in the construction of identity. Additionally, Kalakovski and Nurmi (1998) showed that adolescents' vocational identity development could be triggered by the institutional transitions they were facing, such as the timing of the differentiation of curriculum into vocational or higher educational tracks. Thus, circumstances existing outside the individuals' personal control may limit their exploration or commitment options (Yoder, 2000). These research findings imply that the vocational identity development of unaccompanied refugees should be considered in relation to their unique refugee experiences, as well as to Norwegian immigration and education policies.

\section{Unaccompanied Minors in Norway}

Norway is one of the major destination countries for unaccompanied minors in Europe (SCEP, 2014). While their asylum applications are processed, children younger than 15 years stay in care-centers run by the Child Welfare Services, CWS. Children 15 years and older are placed in special reception centers regulated by the Norwegian Directorate of Immigration. 
Young asylum seekers are entitled to start school soon after arrival in the care and reception centers.

When the children are granted asylum, or residence on other premises, they are offered resettlement in municipalities all over the country where local institutions are responsible for scaffolding their care and support. A majority of the children, $60 \%$, receives intervention by the CWS, which according to the Child Welfare Act $§ 1-3$ may continue, if they consent to it, from $18-23$ years. The two most frequent interventions are supported living arrangement in small group homes of $4-6$ residents, staffed according to their age range, which applies to $55 \%$; and economic support that applies to $59 \%$. Only about $15 \%$ of the children, typically the youngest, are placed in foster care (Haugen \& Dyrhaug, 2014).

Education in Norway is free, even at the tertiary level. Elementary school involves grades one through seven (ages 6 - 12 years), followed by three years of lower secondary school (ages 13 - 15 years). Tracking into vocational and university-bound streams starts in upper secondary school, which includes grades 11 through 13 (ages 16-18 years). Some vocational tracks with apprenticeships may last five years. Younger unaccompanied minors typically enter the public schools, whereas older children are offered introductory language courses and special programs to learn the curriculum of lost school years before entering upper secondary school.

\section{The Present Study}

The overall aim of this exploratory study is to examine factors impacting the educational aspirations and vocational identity development of youth who arrived in Norway as unaccompanied minor asylum seekers. More specifically, we examine the following questions: 
Phase 1:

1. Do demographic factors, pre-migration trauma, and post-resettlement acculturation and mental health predict variation in their educational aspirations?

Phase 2:

2. To what extent do unaccompanied refugees engage in identity forming processes of exploring and committing to vocational possibilities, values and roles? Are they active partners, resulting in moratorium or achieved vocational identity statuses, or do they tend to follow the advice of perceived significant others, resulting in a high prevalence of foreclosed identity statuses? Does the high level of mental health problems contribute to disinterested and disengaged ways of dealing with educational choices, thus resulting in diffused vocational identities?

3. What common core themes and common barriers related to structural, economic, social, and cultural factors underlie the vocational identity formation process of unaccompanied refugees?

\section{Method}

The study employed a mixed method design to obtain different, but complementary data on the research questions by combining quantitative and qualitative procedures.

\section{Phase 1. The Quantitative Study Sample}

The first phase of this investigation examined questionnaire data from a population based multi-ethnic sample of unaccompanied refugees who were granted residence in Norway between 2000 and 2010, $n=918$, and were resettled all over Norway. The large majority, $82.1 \%$, were boys, reflecting the general gender distribution of unaccompanied minors in Europe. The majority came from Afghanistan (51\%), Somalia (12\%), Iraq (7\%), and Sri 
Lanka (6\%) while the remaining $24 \%$ represented 30 other national groups. The mixedmethod longitudinal study involved four Waves of data collection with about one year between each of them. The study was approved by the Norwegian Data Inspectorate and the Regional Committees for Medical and Health Research. Participants 16 years or more signed the consent forms, while for the younger children their legal guardians were asked to sign together with the informants. Unaccompanied minors residing in 41 municipalities nationwide were invited to participate. They met in groups at a familiar place in their local community. The questionnaires' language was Norwegian, and a protocol with standardized explanations of difficult expressions, and translation to English, was available to the trained research assistants administering the material. Only $15 \%$ of the sample accepted the offer to have available translators who could read the questions in their mother tongue, and only for Wave 1. More details about sampling and data collection procedures are available in other studies (Keles, Friborg, Idsoe, Sirin, \& Oppedal, 2015a; Oppedal \& Idsoe, 2015). The participants were, on average, 18.61 years old (SD 2.61), they had a mean length of stay of 3.42 years (SD 2.27), and 77\% reported that one or both parents were dead, or they did not know if their parents were alive.

Pre-migration and ongoing education. Almost half the sample had not attended school $(21.5 \%)$ before arrival in Norway, or they had only attended school $1-3$ years (25.7\%). The other half had $4-7$ years of schooling before arrival $(28.8 \%)$ or 8 years or more (19.4\%), while $4.7 \%$ did not know how much education they had received before migrating. The length of pre-migration education was not associated with the children's average age at arrival.

Only $32(3.5 \%)$ of the participants had finished college or university at Wave 1, and $135(14.7 \%)$ had finished upper secondary school, of which $59.3 \%$ were from vocational 
tracks while $10.9 \%$ were still attending introductory courses of Norwegian language and social studies. The majority of the remaining participants, $312(36.5 \%)$ attended elementary or lower secondary education within the public school system, or were in adult education classes for immigrants (29.9\%). Seventy-six participants (9.1\%) worked full time, while only three reported to be unemployed and not participating in any form of education.

\section{Phase 1 Measures}

Education related aspirations were measured with one question about the highest level of education the participants were planning on fulfilling with five response categories according to the Norwegian education structure: 0 (not yet decided) 1 (upper secondary vocational), 2 (upper secondary theoretical, university bound stream), 3 (3 - 4 years undergraduate university/college), 4 (4 - 7 years graduate university/college).

Demographic information about the participants' age and length of stay in Norway was provided by the Norwegian Directorate of Immigration, while gender and years of schooling prior to migration was self-reported.

Depressive symptoms was measured by the Center for Epidemiological Studies Depression Scale, CES-D for adolescents (Radloff, 1991). CES-D assesses how often during the last week the individual has experienced 20 symptoms $(\alpha=.84)$ such as "I was bothered by things that usually don't bother me". Response categories range from 0 (rarely/never) to 3 (most of the time/all the time), and the total score ranges from 0 (no symptoms) to 60 (frequent high levels of symptoms). CES-D is frequently employed in epidemiological studies, and has demonstrated good psychometric qualities across ethnic groups (Porte \& Torney-Purta, 1987; Pretorius, 1991). The Norwegian version was translated for a previous study by standard back-translation methods (Clausen \& Slagsvold, 2005). The four dimension factor structure with one latent factor was confirmed in another study (Keles et al., 2015a), 
and structural equivalence was confirmed across gender and ethnic groups (Oppedal \& Idsoe, 2011).

Symptoms of Post-traumatic stress, PTSD were measured by Children's Revised Impact of Event Scale-8, CRIES-8 (Perrin, Meiser-Stedman, \& Smith, 2005). CRIES-8 ( $\alpha=$ .73 ) is designed to screen children and adolescents at risk for PTSD, and includes four symptoms of intrusive thoughts and memories; "Do you think about it even when you don't mean to?" and four items of avoidant behavior; "Do you try to remove it from your memory?" The participants were asked if they had been exposed to traumatic events prior to entering Norway, and if they had, to indicate how often during the last week they had experienced each symptom. Items are scored 0 (not at all), 1 (rarely), 3 (sometimes), and 5 (often), with the total score ranging from 0 (no symptoms) to 40 (frequent high levels of symptoms).

CIRES-8 is currently being employed worldwide in zones of war and disaster and demonstrates good psychometric properties cross-culturally. It is available at Children and War Foundation in a variety of languages, including Norwegian (www.childrenandwar.org).

Pre-migration traumatic exposure was indicated by a list of eight dichotomous (yes / no) items of the type and numbers of traumatic events experienced before arrival in Norway, covering family, illness, war experience, physical violence, in addition to an open question about other events as suggested by Bean et al (2006). (Bean, Derluyn, Eurelings-Bontekoe, Broekaert, \& Spinhoven, 2006). A sum-score of the total number of traumatic events, ranging from 0 to 8 , was calculated.

Perceived discrimination was measured by five items $(\alpha=.73)$ indicating varying degrees of discrimination, ranging from having been treated unfairly or negatively to having been attacked because of one's cultural background. The measure was developed and translated for the purpose of The International Comparative Study of Ethnocultural Youth 
(ICSEY) and has been used widely (Berry, Phinney, Sam, \& Vedder, 2006). Respondents checked how much they agreed to e.g. "I have been teased or offended because of my cultural background" from 1(strongly disagree) to 4 (strongly agree) (Berry et al., 1993). A mean sum score was calculated with total score from 1 (no discrimination) to 4 (high discrimination).

Host (Norwegian) Culture Competence was assessed by nine items $(\alpha=.85)$ about knowledge and skills of verbal communication and patterns of social interaction and behavior (Dalhaug, Oppedal, \& Røysamb, 2011; Oppedal \& Idsoe, 2015). The participants checked on a four point scale from 1 (very difficult) to 4 (very easy) how easy it is for them "... to speak Norwegian”, and “... to know how to behave when visiting ethnic Norwegian friends”. A mean sum score was calculated with total score from 1 (low competence) to 4 (high competence). The cross-cultural factor structure equivalence of the measure was confirmed in a recent study (Oppedal, Keles, Chea, \& Roysamb, 2016).

Missing data for these variables varied from $2.5 \%$ on depression to $14.7 \%$ on trauma.

\section{Phase 2. The Qualitative Study Sample}

The second stage involved examining recorded semi-structured interviews with 30 participants from the larger sample to distinguish issues impacting the vocational identity formation processes. The recordings provided audible results for the transcription of 29 out of 30 interviews. In order to reach interviewees with good Norwegian language proficiency, inclusion criteria for the interview sample was that they had been in Norway two years or more, and that they were participants in one of the later Waves $\left(2^{\text {nd }}, 3^{\text {rd }}\right.$, or $4^{\text {th })}$ of data collection from the larger study described in Phase 1. Requests for interviews were sent out several days before the annual questionnaire data collection was to take place in their respective municipalities, and the interviews were carried out on the day after they completed the questionnaires. The interviewees' mean age was $20.15(S D=2.21)$, and they had an 
average length of stay in Norway of 4.30 years $(S D=1.19)$. They were from Afghanistan (46.7 \%), Sri Lanka (13.3\%), Somalia (10\%), and Iraq (10\%), while $20 \%$ came from four other countries, and $86.7 \%$ were boys. The interview sample did not differ significantly from the larger sample in terms of national background, gender, age, length of stay in Norway, number of traumatic events reported, or level of symptoms of depression and PTSD symptoms.

\section{The Interview Protocol}

The interview protocol that was used in Phase 2 is an extension of Marcia et al.'s (1993) Identity Status Interview, ISI, in which exploration and commitment processes in the following identity domains were examined: education, heritage culture, and Norwegian culture. In accordance with the ISI scoring manual (Marcia et al., 1993), the emotional tone of the interview is considered in addition to the degree of depth in exploration and commitment processes within any given domain. Marcia's identity status paradigm and assessment scheme has been widely applied in a variety of western and non-western contexts, including North America, various countries in Western Europe, New Zealand, Nigeria, Japan, India, Ghana, South Korea, Eqypt, Israel (with Bedouin and Jewish participants), Russia, Jordan, Lebanon, Iran, the Cameroons, Trinidad and Tobago. For reviews, see (Kroger, 2015) and (Marcia et al., 1993). To examine exploration and commitment within vocational and ethnic identity domains among unaccompanied refugees, the ISI paradigm (Marcia et al., 1993) was adapted specifically to these topics and this target group by the research team, under the guidance of two senior researchers with a long standing expertise in the field of identity development and psychological adjustment of refugee youth. Adaptations involved identifying those whom the youth perceived as significant others in their home countries as well as in Norway, accommodation of questions of exploration and commitment to the special school situations 
of the participants, and examination of both heritage and majority culture ethnic identifications. For the purpose of the present investigation, only material relevant to the domain of vocational identity development is examined.

A team of graduate student interviewers were trained in the rating and administration of the ISI. All interviews were tape-recorded and transcribed for subsequent analysis.

While the ISI has most commonly been administered to identify an individual's likely identity status, considered as a global rating or in terms of individual identity domains, the ISI also provides detailed information regarding the types of both internal as well as external circumstances associated with individual identity development. Individual life stories that have emerged in conjunction with the ISI have also been the subject of a growing number of qualitative analyses over past decades (Carlsson, Wängqvist, \& Frisén, 2015; Josselson, 1996; Kroger, 1993, 2002) and are used here as the basis for addressing Study Questions 2 and 3.

\section{Analyses}

All 29 transcribed interviews were read and coded for identity status, i.e. if the participants had or were engaged in processes of exploration and commitment of vocational alternatives, independently by two researchers. In cases of disagreement, an identity status was assigned following discussion. A third researcher with expertise in the field of identity status coding, read and independently coded 13 interviews, (inter-rater reliability = .77; Cohen's Kappa = .62). These reliabilities are within commonly accepted ranges for the ISI (Marcia et al., 1993).

The analyses of the interviews also involved meaning categorization analysis (Kvale, 1996) by which the interviews were coded into categories, identifying recurring themes, patterns and variations within the data set in relation to the study questions. Using QSR 
International's NVivo 10 Software and categorization techniques, a number of broad categories of events impacting vocational identity decisions were identified, and all data fragments that were related to each category were rearranged into new data sets. In this way, long sentences and narratives reflecting the minors' experiences and perspectives were reduced and structured into categories such as "education in the country of origin," "discrimination," and "significant others in Norway" that could be linked with scientific theory in the field (Kvale, 1996). These categories appear as main themes in the results from Phase 2 of this investigation.

\section{Results}

\section{Phase 1. Predictors of Educational Aspirations}

In the quantitative sample the participants' educational aspirations were quite evenly distributed on the various response categories: About one fifth $(22.3 \%)$ had not yet made decisions about level of education and $25.7 \%$ aspired to a vocational track of upper secondary school, while only a small minority (4.2\%) had the theoretical, university bound track of upper secondary as their aspiration. An additional $26.1 \%$ and $21.6 \%$ aimed at undergraduate and graduate degrees from college or university respectively. Boys reported lower levels of aspirations $(M=1.90, S D=1.53)$ than girls $(M=2.41, S D=1.35), t(849)=-$ $3.79, p<.001$. A closer look at the responses confirmed that more girls than boys planned on undergraduate studies (46.4\% vs $21.6 \%$ ), whereas more boys than girls aspired to a vocational degree from upper secondary school (27.5\% vs $17.6 \%)$. Neither the participants' age nor their length of stay in Norway were associated with aspirations ( $r=-.04, n s$. and $r=-.05, n s$, respectively). The means, standard deviations, and correlations for all included variables are shown in Table 1. The mean level of depression symptoms was close to the suggested clinical cut-off of 23 (Roberts, Lewinsohn, \& Seeley, 1991), and the mean level of PTSD symptoms 
was above the suggested clinical cut-off of 17 (Perrin et al., 2005), confirming earlier findings that unaccompanied minors represent a vulnerable group with respect to mental health problems. Nevertheless, they perceived themselves as competent with respect host (Norwegian) culture competence, with an average score of 2.69 on a scale from 1 to 4.

Noteworthy, initial exploration of the correlations between educational aspirations and mental health and psychosocial predictors showed that the associations were either nonsignificant, or rather small, ranging from -.003 (trauma) to .11 (PTSD).

To investigate the combined effects of these variables on educational aspirations, we performed hierarchical regression analyses. In the first Model, we entered demographic background information in terms of gender, length of stay in Norway, and age. Symptoms of depression and PTSD were entered in Model 2, followed by pre-migration traumatic events, and post-migration discrimination and host culture competence in Model 3. None of the predictors reached significance in the multi-variate analyses. When controlling for age and length of stay, the gender difference in aspiration disappeared $(B=.24, S E=.29, \beta=.06 n s)$. Importantly, the variation in aspiration was not accounted for by the included variables of demographics, mental health, pre-migration trauma, post-migration stress or resources; adjusted $r^{2}=-.002$.

\section{Phase 2: ISI Ratings and Factors Impacting Vocational Identity Decision-Making}

Table 2 gives an overview of the ISI subsample's characteristics, ratings, and current educational situation. Based on an assessment, the distribution of vocational ISI ratings for the 29 interviewees was as follows: Achievement, $\mathrm{A}(n=13 ; 45 \%)$, Moratorium, $\mathrm{M}(n=5 ; 17 \%)$, Foreclosure, $\mathrm{F}(n=6 ; 21 \%)$, and Diffusion, $\mathrm{D}(n=5 ; 17 \%)$.

\section{Significant Others}


Identifying peers and adults that play an important role as figures for identification, discussion partners, and/or advisors in the identity formation choices youth make is a central purpose of the ISI.

The family. One of the most striking findings from the interviews was the negligible role parents or other family members played in the participant's identity formation process. Even participants who had contact with family abroad did not perceive them as discussion partners in this process. For many, the knowledge and background of close relatives was considered irrelevant for these youth in the context of their current lives and the educational choices they needed to make. For instance, one participant reflected on a question about the education of her parents:

I have never been interested, really. I have never asked them either. They went to school, but I don't think my mother had any education, it was a more old fashioned culture, women are often at home and men work. My father worked in the municipality. I remember that he took part in making decisions about something in the municipality, and so on (\#12 ${ }^{1}$ : Female, 19. ISI-rating: D).

Most of those interviewed reported that parents did not interfere with the educational choices made by their refugee children:

Interviewer: Did you talk with your mother about your choice?

Youth: She said it was up to me, that I should decide Interviewer: You are the one who decides?

\footnotetext{
${ }^{1}$ The numbers refer to interview number in Table 2, and the participants' age
} 
Youth: Yes, as long as I study. The only thing she thinks about is that I have to study. And get a job and make it. (\#20: Male, 22. ISI-rating: M).

Even relatives residing in Norway did not play an active part in the educational decisions of the unaccompanied refugees, but instead simply encouraged them to choose something that interested them.

The friends. For most of the participants, the peer networks of the participants included unaccompanied refugee youth and other immigrants from their own or other countries, in addition to ethnic Norwegians. However, the latter did not seem to play any important part either as role models or as cultural brokers in the educational decision- making processes. One important reason for this appeared to be that, because of the way that education is structured for unaccompanied refugees, their ethnic Norwegian classmates are usually several years younger, and consequently perceived as quite immature. For instance, when asked if he had Norwegian friends one participant responded:

It is somehow difficult, yes, especially those who are in my class. I am 20 now, they are 17 or 18 , they are still a little bit childish, or how I should put it? (\#10: Male, 20. ISI-rating: A).

Another important barrier to establishing friendship with ethnic Norwegians was the perception of being discriminated against and not being acknowledged:

Interviewer: Do you have good friends who are ethnic Norwegians?

Youth: Not so many. With youth it is a little bit hard, but I, because, they don't easily accept foreigners, right? It takes time until you get to know them, and they accept you as a friend. (\#10: Male, 20. ISI-rating: A). 
In addition to the age gap and discrimination, the major differences between ethnic Norwegians and unaccompanied refugees in general life situations meant that it was complicated, and made little sense, for many participants to discuss future educational pathways with them. As one participant explained:

The difference between me and a Norwegian youth is that they have parents. They don't need to think so much about earning a living. They can still live with their parents when they are 20, 25, 30. And so, I chose Health and Social Sciences. It is a little easier, and a faster route to getting a job (\#15: Male, 21. ISI-rating: D).

For many their immigrant friends could have an influence. If a participant in the moratorium stage was considering different available vocational options, having a friend with the same interests could be important in making a decision:

Interviewer (to a participant who had considered data-engineering and accounting, and decided on the latter): Can you tell me more about how you made this decision, what you did to be able to make a decision?

Youth: I attended an (educational) exposition and so on. ... Then I looked at the internet. And I have a friend who I have been going to school with since, like I came here, we were in the same classroom.

Interviewer: All the time?

Youth: All the time. Except for one year. And he also had an interest in it (accounting).

Interviewer: OK, and so the two of you started together?

Youth: Yes

Interviewer: (...) So you talked a lot with him about this choice then?

Youth: Yes. (\#1: Male, 22, ISI-rating: A). 
Other significant adults. Although suggestions from other immigrant friends were important to some participants, most of them considered the advice from adults to be more valuable:

I tend to have more trust in adults, when it comes to advice about the future. Or rather, it is not that I don't trust my friends, but adults have experience. So they know what is right or wrong (\#14: Male, 21. ISI-rating: A).

The people that the youth most frequently mentioned as having been influential in their decision making were the school counselors, and sometimes their teachers, responsible for explaining the structure and different educational trajectories of upper secondary school to the students before their transition. However, the preconceived assumptions these professionals had about the unaccompanied minors' abilities, in particular regarding their Norwegian language competence, appeared to be an important factor underlying the advice they gave, and these professionals were therefore not always perceived as helpful:

It was the counselor who gave me, like, bad advice. Because you become ... since you don't know much Norwegian and so on, so you should attend an easy program (\#20: Male, 22. ISI-rating: M).

Another youth who was very interested in history explained how he instead ended up studying process technique since the teacher assumed that language barriers would make it difficult for him to get a university degree in history and subsequently a job:

Interviewer: You are a production worker at a factory, and have an education in process technique. Can you tell me a little bit about how you became interested in this field?

Youth: Uhm, yes I was thinking about how I can get a job. And then I heard from 
a teacher that this program is easier than the others.

Interviewer: Oh yeah? It was a teacher who told you?

Youth: Who told me, yes. But actually I am (more) interested in history.

Interviewer: You are interested in history?

Youth: Yes, but it isn't easy to get a job with that kind of education (if you don't speak Norwegian well), so I just chose chemistry (\#18: Male, 25. ISI-rating: D).

Other professionals, such as social workers in the group homes or in the social welfare services were also partners in the decision making process, as was the case for one girl who reflected on how she decided on the Health and Social Service program:

I always knew that I liked to help people, and in particular, children, I want to work with children. Yes, and so I thought that,- since I arrived here, I lived with others and observed that there are social workers who help out all the time, right, and then I decided to become a social worker ... I liked to talk with them, and they talked about being a social worker, and I said, okay, I always knew I wanted to work with people (\#19: Female, 21. ISI-rating: A).

Additionally, employers, colleagues, adults in a family they had become friendly with, a psychologist, and a landlord were described as having had a certain influence in their decision making. These relationships appeared to be sporadic and lacking continuity, indicating how fragile the relationships with supportive adults are for the unaccompanied refugees. In some youths, this provoked feelings of the loneliness and the burden of having only oneself to rely on, as one participant who was disappointed with the lack of help he got from his counselor, described:

There are many counselors who are not able (to give advice). So he said he did not know. I called a school and that's what they said. So I thought to myself; I am fed 
up with this, and then I just applied through the school's website for example. So

really I found more information myself, than the counselor had (\#14: Male, 21, ISI-rating: A).

These accounts of the ways the participants access and utilize available resources to get necessary information and advice are again a demonstration of their agency and strong will to resolve challenges and be successful in their resettlement country.

Core Themes, and Contextual Barriers Emerging from the ISIs

The main themes that emerged from the interviewees' reflections on their vocational choices were often intertwined with a series of contextual barriers that they perceived as limiting the educational trajectories available to them.

Age, time, and economy. Table 2 shows that the majority of the interviewees were in the age range beyond secondary education; however, as a consequence of having lost years of education due to war and flight, most of them were attending upper secondary school. This reality also had economic consequences, as valuable financial support from the CWS ceases when the clients turn 23 years. Living alone and being in charge of their own economic resources without adult social support was a tough challenge for many youths. Thus, the economic implications of the age gap weighted heavily in the identity developmental processes underlying their educational/vocational choices. This is illustrated in the contemplations of one participant who said that he really wanted to become a policeman or a doctor, but the prospect of lack of financial help in early adulthood had made him decide on a vocational track that prepared him to enter the work force after finishing upper secondary school: 
Interviewer: If you had the opportunity to become a policeman or doctor, would you rather have done it?

Informant: Yes, of course.

Interviewer: Yes, what keeps you from doing it?

Informant: Well, it takes a long time to study and attend school. And what is worse is that after I am 20 years, I won't get as much (financial) help. So it becomes very hard (\#8: Male, 19. ISI-rating: M).

Moreover, according to The Education Act about Primary and Secondary Education and Training (1998), one's right to upper secondary education has to be used before the age of 25 (§ 3-1), enforcing more competition with time on the unaccompanied refugees. A consistent consequence of the age-time-economy dynamics was that the youth decided to attend a vocational track in upper secondary school to have a profession that would provide them with a living in a short time. While some had dreams of starting their own businesses, others thought of this as a first step to getting a job and working for a couple of years, and subsequently starting off a college career when they could support themselves economically:

Interviewer (asking a participant in the electro program of the vocational track how he became interested in this specific subject): But at first you said that you wanted to attend the theoretical (university preparing) track?

Youth: Yes.

Interviewer: Yes. Did you have any thoughts about what kind of education you wanted if you attended this?

Youth: Yes. Medical doctor or lawyer.

Interviewer: Medical doctor or lawyer? Those educations take a long time?

Youth: Then I thought about being certified as an electrician, work for some time, 
and then I can study more (in college/university) to qualify for a degree as an engineer (\#13. Male, 17, ISI-rating: F).

Mental health. Three ISI-participants talked specifically about the difficulties their mental health problems had caused them in their daily activities, and how they were still struggling. One boy was resentful of not having been offered adequate help and thus had not been able to plan any future education on his own when graduating from upper secondary school:

Interviewer: Have you thought about what kind of education or job you would like to have?

Informant: If I had thought about it, I would have succeeded with it. If I had thought about it deliberately, but I feel that I did not get the help I needed after I finished upper secondary school. I was down and completely empty in my head and did not get the right help.

Interviewer: No? Did you seek help anywhere?

Informant: No. I don't have any father or mother I can ask.

Interviewer: No, but a social worker or counselor or somebody who could help you?

Informant: They don't function the way you think they function. They work very... differently from what we need (\#16: Male, 27. ISI-rating: D).

The young man appeared distressed, he had not engaged in any further education after secondary school in spite of having been in Norway for 11 years, he was not gainfully employed, but did some voluntary work for a non-governmental organization.

Another youth described how he was striving to get away from some former friends that he learned could not be trusted at the same time as he suffered three serious losses among 
his best friends; he seemed seriously distressed, and anxious, and at times incoherent in his interview. He was striving to put the past behind and be optimistic about the future. He was strongly dedicated to his plan to get on with his life. He had recently finished upper secondary school with an apprenticeship certificate, had temporary employment, and was working on the next step:

Music has always been my plan. But the most, the biggest plan for me, is to live.

To confront everything; I have to confront life with a big smile. That is the plan. I don't want to sit with those (thoughts), to have an empty heart every single day. And worry about things I cannot do anything with (\#17: Male, 22. ISI-rating: D).

In contrast to the above participants, one participant had been treated for the PTSD he had suffered from for years. This had made it possible for him, after 9 years in Norway, to finally enter and fully dedicate himself to a vocational program of upper secondary school. His ISI-rating was A, but apparently the PTSD symptoms had previously prevented him from engaging in educational identity forming processes.

Transnational lives. The transnational reality of unaccompanied refugees with close ties to family members who had stayed behind, and memories of the villages they had left, was mirrored in the vocational choices of several participants. The awareness of the harsh lives of family members abroad and concern for the well-being of people in the communities they had left, were important factors in their exploration of vocational alternatives. For example, one participant had decided to become a nurse, because there was a need for nurses in Myanmar. Another, who together with friends in upper secondary school had organized the building of a well in his village, explained:

Interviewer: How did you find out that you wanted to become an engineer? Did you talk to anybody about it? 
Youth: Yes, and I was actually thinking about my home country. So the village that I come from, they need electricians there. So if I become an electrician, I can work here, and at the same time I can help the people in my home country.

(\#7: Male, 22. ISI-rating: A).

For others, their vocational choices were based in the urgent needs of impoverished family members, internally displaced, in refugee camps, or in villages where all infrastructure was ruined from years of war:

Youth: They (parents) expect me to become something like, something else, something with a higher education, or a doctor, or (laughs) Interviewer: They expect that?

Youth: Lawyer, that sort of thing. But I told them that I don't have that opportunity, or it is like this, if you don't want money from me, then I can sit and study for 5 or 10 years, then I can become a... have a real, a good job and so on. But, they want money from me, so I can't just study for many years, you know? Interviewer: Was that important for you when you made the choice of a vocational program instead of a theoretical track; not to have such a long education?

Youth: I needed to make some money, right? I didn’t feel that I will study for 20 years, and then afterwards I can start working and make money. That's what I thought about (\#10: Male, 20. ISI-rating: A).

Realistic assessment of contextual barriers. The need to make realistic assessments of their situations, their opportunities and barriers in relation to future career paths, was a recurrent theme in the interviews. Most of our informants seemed determined to complete their education, enter the work-force, and create meaningful futures. But they were acutely aware of their vulnerable situations, including coping with past trauma, acculturation, lack of 
sufficient social support networks, the responsibility to support family in the home country, language barriers, insufficient schooling in their home countries, and discrimination. Taking into account these factors, the youths seemed to weigh their knowledge and skills against realistic vocational opportunities in the resettlement context:

Interviewer: What made you interested in (becoming an engineer)?

Youth: Well ... I thought that, engineer and that sort of thing, it is easier to get a job than ... Politician, I think like, I could never become a good politician, not in Norway at least ... But an engineer is more realistic.

Interviewer: Is there something you like about that education or line of work that tempted you?

Youth: Uhm, actually, it is the mathematics that I prefer (\#5: Male, 20. ISI-rating: M).

The participant explored alternatives such as political science and mathematics in addition to engineering. Considering his own abilities, he did not find political science a good choice, while he believed that it would be hard to get a job with a degree in mathematics. Thus engineering appeared the most realistic alternative to him in the given context, both with respect to his own competence and the opportunities of the job market. Importantly, these youths' assessments of their situation and possibilities, often implied that individual dreams, aspirations, and preferred identity options were outweighed by their considerations of the necessity to enter the work force rapidly, and become economically independent.

Some participants reflected on experiences of discrimination both in terms of having been victims of unequal treatment because of their ethnicity, and harsh, insulting, offensive behavior. One youth reported the obstacles he had been confronted with in pursuing his career as a plumber: 
Youth: And I have attended two years of upper secondary school in the vocational program of plumbing at the (name) high school. And then, since I could not get an apprenticeship, I did the supplementary courses for the theoretical tracks; And this has to do with kind of discrimination thing. Even if I had good grades and hardly any absences.

Interviewer: You still did not succeed (in getting an apprenticeship)?

Youth: No, I still did not succeed. I have tried from A to $\mathrm{Z}$ all the companies in this and the neighboring counties. I went from door to door and knocked to ask for a place, ... but in some way or other I was always turned down. Then I did not have other choices than to do the supplementary course (\#2: Male, 23. ISI-rating: F).

Another participant reflected on the behavior of an alcoholic boss where he had an apprenticeship. The foreman always yelled at him and called him a nigger. However, his colleagues supported him and advised him to cope with it until he could get his apprentice certificate.

In spite of the several barriers and hardships these unaccompanied refugees were exposed to, the findings from these interviews clearly echoed that the majority of the youths were prepared to adapt and reassess their individual aspirations. They displayed impressive willpower to make it through the school system, in order to get an education and secure a job and an income for themselves.

\section{Discussion}

The overall aim of this study was to examine factors impacting the educational aspirations and vocational identity development of unaccompanied refugees in Norway. A major strength of the study was its mixed-method design providing quantitative data on a 
large number of participants as well as rich qualitative data. Based on questionnaire data from 918 unaccompanied refugees, we first examined the effect of demographic, pre-migration trauma, mental health, and acculturation related factors on their educational aspirations. Next, we investigated semi-structured interview data from 29 participants to get a deeper understanding of the deliberations and concerns underlying the identity-defining decisions they had made about education and work.

Interestingly, important societal contexts such as the European economic crisis and associated youth unemployment did not seem to play an important part in the interviewees' identity struggles. On the contrary, the common themes were related to proximal refugee context of economy and regulations regarding CWS and national educational laws. This may be a result of Norway not having been hit so hard by the economic crisis as several other European countries. Or, it could be an expression of the refugees' educational ambitions, disregarding the economic situation of their receiving countries, as has been shown in previous studies (Shakya et al., 2010). Educational policies and practices should target the resources of unaccompanied refugee youths rather than their limitations, and interventions should focus on supporting and strengthening their ambitions during stages of late adolescent identity development.

\section{Predictors of Educational Aspirations}

None of the demographic variables or indicators of pre-migration trauma, mental health, and acculturation-related experiences yielded significant effects on aspirations in multi-variate analyses. There was no effect of the amount of traumatic events they had experienced, mental health problems they were suffering from, or any other predictors on how ambitious these youths were with respect to their education. Whether they were undecided, aspired for a short vocational education or for a higher university degree could not be 
explained by variables found to predict educational aspirations in other studies (Chung, Loeb, \& Gonzo, 1996; Nadeem \& Ringle, 2016; Wong, Eccles, \& Sameroff, 2003). These unexpected findings are probably associated with immigrant optimism and a generally strong wish among unaccompanied minors to create a better life for themselves than what they had before they started off to Europe and Norway (Hopkins \& Hill, 2008; Oien, 2010); and may speak to the unique experience of unaccompanied minors relative to other migrant youth in prior studies. Their dream, their goal, their number one priority seemed to be to get an education and start providing for themselves economically, irrespective of age, how long they have been resettled, or their everyday psychosocial functioning. Future research should include variables identified in the interviews as predictors of aspiration, and explore the potential for moderator effects by social, cultural, and migration background factors.

\section{ISI-ratings}

Next we examined how much the unaccompanied refugees engaged in identity forming processes of exploration and commitment to possibilities, values and roles. The results show that their identity status distributions were very comparable to the global identity status distributions of individuals of similar ages in other western countries who have not undergone such adversities (Kroger, Martinussen, \& Marcia, 2010). Clearly well over half of the interviewees (62\%) were engaged in vocational identity-defining processes. Some $45 \%$ had made commitments following exploration, and a further $17 \%$ were in the process of vocational identity exploration. In addition, $21 \%$ of the sample had formed vocational identity-defining commitments, without preceding exploration. However, the foreclosed commitments did not appear to be conferred by significant others, as is generally the case. Rather, participants made up their minds quickly when faced with the educational options 
available to them, and then did not seriously consider alternatives, keeping to their original decisions.

Considering the pre-migration traumas they had faced, and their challenges in adapting to their resettlement country, the high proportions of individuals able to search and/or form educational identity commitments may imply that this is an extraordinary and highly resilient group of refugees (Keles, Friborg, Idsoe, Sirin, \& Oppedal, 2015b).

\section{Core Themes and Contextual Factors Underlying Educational Identity Development}

The results of the qualitative analyses of the ISIs contribute information about the motives and priorities explaining the educational aspirations and decisions made by unaccompanied refugees that the findings from Phase 1 failed to yield. Core to their educational/vocational choices were issues related to their transnational identities, barriers of mental health problems, discrimination, their perceived academic self-efficacy, and Norwegian language competence.

However, the theme most frequently identified from the ISI interviews revolved around age, time, and economics. Their lack of age-relevant formal education prior to arriving in Norway appeared not only to be basic to their exploration and assessment of the different educational/vocational trajectories available to them, but also to be a barrier in their sociocultural integration into the Norwegian society. After years of catching up with the Norwegian curriculum, many of them were well into the age of tertiary education when they entered upper secondary schools. They found their classmates immature, which reinforced their out-of-school friendships, often with other unaccompanied refugees they became acquainted with in the reception centers or group homes. Most importantly, many of them were approaching the age when the support from CWS and their rights to be enrolled in upper secondary school would be discontinued. Based on this, many unaccompanied refugees chose 
vocational programs over theoretical tracks with the perspectives of a university degree.

Moreover, their challenging economic situations in this stage of resettlement (Oppedal, Seglem, \& Jensen, 2009) probably further contributed to their strong motivations to become economically independent. Rather than considering work as a means for self-realization, they were seeking safe employment to earn money quickly. However, many of them maintained an ambition and a dream to enter higher education in the future.

Another important theme that materialized through the ISIs was the scarcity of lasting supportive adult relationships that the unaccompanied refugees could rely on, both when dealing with difficulties with psychological adjustment, and when they transitioned to new developmental stages. Family and friends were not important partners in their vocational identity development, and the school professionals' counseling of the youth about educational choices appeared to be a business-like goal-oriented matter. Previous research in Norway has shown that the support system prioritizes preparing the youths to be independent and assume responsibility for their own lives by securing any job, disregarding other important developmental concerns (Eide, Guribye, \& Liden, 2014).

\section{Limitations}

The participants had, on average, been in Norway for 3.42 years at W1 data-collection. Nevertheless, at W2 about a year later (minimum condition for participating in interviews), none of them requested a translator. Not surprisingly, during data-collection it was clear that the receptive language of the youth was very good, while the expressive language was more limited. This may have resulted in less than ideal information and some potential mistakes in the coding process. Nevertheless, an important dimension of coding the ISIs is the interviewee's emotional tone, and the reliability between the coders was acceptable. Future interviews carried out by bilingual interviewers could shed light on the methodological 
challenges associated with limited expressive Norwegian language proficiency of the interviewees.

The quantitative part of the study was based on self-report cross-sectional data, with all the inherent limitations, such as inflated mono-method variance. However, it is not easy to identify reliable sources for unaccompanied refugee youths' mental health. Data collected from legal guardians in a Dutch study revealed some discrepancies compared to self-report of the mental problems experienced by these youth (Bean, Eurelings-Bontekoe, \& Spinhoven, 2007). Importantly, the research literature has confirmed that internalizing problems are more reliably assessed when self-reported (Achenbach, 1991). The lack of other-informant perspective also applies to the qualitative study. We know little about the perspectives, experiences, and expectations of, for example, the counselors who some participants perceive as either incompetent or lacking in insights into their ambitions and competence. Information about the assumptions adults make in counselling young refugees and their perceptions of barriers and opportunities in vocational trajectories could be helpful in identifying the potential for improvements of the vocational guidance processes in refugee contexts.

The CES-D and CRIES-8 have not been clinically validated in Norway, and we do not know to what extent the responses are influenced by cultural factors, such as the culturally based variation in response set or the understanding of concepts and response alternatives.

\section{Conclusions}

One important finding from this study was the lack of social support resources available to the unaccompanied refugees in this important developmental stage. This finding has consequences for social inclusion beyond those of vocational identity formation. In Norway, care and support for the developmental well-being of unaccompanied minors is structured by the limited resources of the CWS and the coincidental presence of NGO's such 
as Red Cross, Save the Children, etc. Policies and practices should focus more attention on establishing lasting and supportive adult relationships in the local communities for this refugee group to promote social inclusion and integration.

In spite of high levels of mental health problems associated with pre-migration trauma and ongoing adaptation challenges, most of the unaccompanied refugees engaged in normative vocational identity formation processes. They commonly reflected actively on their realistic choices as unaccompanied refugees in the Norwegian educational system and labor market. They are striving to find balance between committing to their own long-term aspirations, and adapting in accordance with their realistic opportunities, sometimes guided by any well-meaning and trusted adult they may be in contact with in Norway. In effect, most of them chose "safe" vocational paths toward earning a living rather than complex roads that led to the realization of their own long-term aspirations. Policy makers may need to consider more long-term strategies for the inclusion of unaccompanied minors in the labor market. By encouraging short-term educations in professions that are often highly affected by recession and cycles in the labor market, an element of instability and vulnerability is maintained. This problem also raises the question to what extent the adults' advice contributes to limiting the aspirations and consequently the social mobility of unaccompanied refugees, rather than encouraging and strengthening their career dreams. 


\section{References}

Baltes, P. B. (1987). Theoretical propositions of life-span developmental psychology: On the dynamics between growth and decline. Developmental Psychology, 23(5), 611-626. doi:10.1037/0012-1649.23.5.611

Baumeister, R. F., \& Muraven, M. (1996). Identity as adaptation to social, cultural, and historical context. Journal of Adolescence, 19(5), 405-416. doi:http://dx.doi.org/10.1006/jado.1996.0039

Baumeister, R. F., Shapiro, J. P., \& Tice, D. M. (1985). Two kinds of identity crisis. Journal of Personality, 53(3), 407-424. doi:10.1111/j.1467-6494.1985.tb00373.x

Bean, T. M., Derluyn, I., Eurelings-Bontekoe, E., Broekaert, E., \& Spinhoven, P. (2006). Validation of the multiple language versions of the Reactions of Adolescents to Traumatic Stress questionnaire. Journal of Traumatic Stress, 19(2), 241-255. doi:10.1002/jts.20093

Bean, T. M., Derluyn, I., Eurelings-Bontekoe, E., Broekaert, E., \& Spinhoven, P. (2007). Comparing Psychological Distress, Traumatic Stress Reactions, and Experiences of Unaccompanied Refugee Minors With Experiences of Adolescents Accompanied by Parents. The Journal of Nervous and Mental Disease, 195(4), 288-297 doi:10.1097/01.nmd.0000243751.49499.93

Bean, T. M., Eurelings-Bontekoe, E., \& Spinhoven, P. (2007). Course and predictors of mental health of unaccompanied refugee minors in the Netherlands: One year followup. Social Science \& Medicine, 64(6), 1204-1215. doi:http://dx.doi.org/10.1016/j.socscimed.2006.11.010

Berry, J. W., Kwak, K., Liebkind, K., Sabattier, C., Sam, D. L., Virta, E., . . Phinney, J. S. (1993). The questionnaire for International Comparative Study of Ethnocultural 
Adolescents (The ICSEY project). The questionnaire for International Comparative Study of Ethnocultural Adolescents.

Berry, J. W., Phinney, J. S., Sam, D. L., \& Vedder, P. (2006). Immigrant youth in cultural transition: Acculturation, identity and adaptation across national contexts. Mahwah, NJ: Lawrence Erlbaum Publishers.

Bosma, H. A., \& Kunnen, E. S. (2001). Determinants and Mechanisms in Ego Identity Development: A Review and Synthesis. Developmental Review, 21(1), 39-66. doi:http://dx.doi.org/10.1006/drev.2000.0514

Carlsson, J., Wängqvist, M., \& Frisén, A. (2015). Identity development in the late twenties: A never ending story. Developmental Psychology, 51(3), 334-345. doi:10.1037/a0038745

Choudhry, M. T., Marelli, E., \& Signorelli, M. (2012). Youth unemployment rate and impact of financial crises. International Journal of Manpower, 33(1), 76-95. doi:doi:10.1108/01437721211212538

Christafis, A. (2015). "Nothing's changed": 10 years after French riots, banlieus remain in crisis The Guardian. Retrieved from https://theguardian.com/international

Chung, Y. B., Loeb, J. W., \& Gonzo, S. T. (1996). Factors predicting the educational and career aspirations of black college freshmen. Journal of Career Development, 23(2), 127-135. doi:10.1007/bf02359292

Clausen, S. E., \& Slagsvold, B. (2005). Aldring og depressive symptomer: En epidemiologisk stydie. (Ageing and depression: An epidemiologic study). Tidsskrift for Norsk Psykologforening, 9, 779-784.

Crocetti, E., Rubini, M., \& Meeus, W. (2008). Capturing the dynamics of identity formation in various ethnic groups: Development and validation of a three-dimensional model. 
Journal of Adolescence, 31(2), 207-222.

doi:http://dx.doi.org/10.1016/j.adolescence.2007.09.002

Dalhaug, K. C., Oppedal, B., \& Røysamb, E. (2011). The role of sociocultural context for culture competence and depressive symptoms among ethnic minority youths in junior high school. European Journal of Developmental Psychology, 8(3), 280-294. doi:10.1080/17405621003710843

Doumen, S., Smits, I., Luyckx, K., Duriez, B., Vanhalst, J., Verschueren, K., \& Goossens, L. (2012). Identity and perceived peer relationship quality in emerging adulthood: The mediating role of attachment-related emotions. Journal of Adolescence, 35(6), 14171425. doi:http://dx.doi.org/10.1016/j.adolescence.2012.01.003

Eide, K., Guribye, E., \& Liden, H. (2014). Refugee children: ambiguity in care and education. In G. Overland, E. Guribye, \& B. Lie (Eds.), Nordic work with traumatised refugees: Do we really care (pp. 119 - 131 ). Newcastle upon Tyne: Cambridge Scholars Publishing.

Erikson, E. H. (1968). Identity Youth and Crisis. New York, NY: W.W.Norton \& Company, Inc.

European Commission. (2015). EU Youth Report. Retrieved from www.ec.europa.eu Flores, L. Y., Navarro, R. L., \& Dewitz, J. (2008). Mexican American High Schools’ PostSecondary Educational Goals: Applying Social Cognitive Career Theory. Journal of Career Assessment. doi:10.1177/1069072708318905

Fuligni, A. J., Witkow, M., \& Garcia, C. (2005). Ethnic Identity and the Academic Adjustment of Adolescents From Mexican, Chinese, and European Backgrounds. Developmental Psychology, 41(5), 799-811. doi:10.1037/0012-1649.41.5.799

Grotevant, H. D. (1987). Toward a Process Model of Identity Formation. Journal of Adolescent Research, 2(3), 203-222. doi:10.1177/074355488723003 
Haugen, J. Å., \& Dyrhaug, T. (2014). Enslige mindreårige flyktninger $i$

barnevernet 2011. Unaccompanied minor refugees within The Child Welfare Services (Statistics Norway 2014/7). Retrieved from Oslo: http://www.ssb.no/sosiale-forholdog-kriminalitet/artikler-og-publikasjoner/_attachment/163066?_ts=14425070930

Hopkins, P. E., \& Hill, M. (2008). Pre-flight experiences and migration stories: the accounts of unaccompanied asylum-seeking children. Children's Geographies, 6(3), 257-268. doi:10.1080/14733280802183981

Josselson, R. (1996). Revising herself. New York, NY: Oxford University Press.

Kalakoski, V., \& Nurmi, J.-E. (1998). Identity and Educational Transitions: Age Differences in Adolescent Exploration and Commitment Related to Education, Occupation, and Family. Journal of Research on Adolescence, 8(1), 29-47.

doi:10.1207/s15327795jra0801_2

Keles, S., Friborg, O., Idsoe, T., Sirin, S. R., \& Oppedal, B. (2015a). Depression among unaccompanied refugees: The relative contribution of general and acculturationspecific daily hassles. Journal of Ethnicity and Health, 21(3), 300-317. doi:doi: $10.1080 / 13557858.2015 .1065310$

Keles, S., Friborg, O., Idsoe, T., Sirin, S. R., \& Oppedal, B. (2015b). Resilience and acculturation among unaccompanied refugee minors Manuscript Submitted For Publication.

Kohli, R. (2007). Social Work with Unaccompanied Asylum Seeking Children. Hampshire: Palgrave MacMillan.

Kroger, J. (1993). On the nature of structural transition in the identity formation process. In J. Kroger (Ed.), Discussions on ego identity (pp. 205-234). Hillsdale, NJ: Lawrence Erlbaum Associates. 
Kroger, J. (2002). Identity Processes and Contents Through the Years of Late Adulthood. Identity, 2(1), 81-99. doi:10.1207/S1532706XID0201_05

Kroger, J. (2015). Identity development through adulthood: The move toward "wholeness". . In K. C. McLean \& M. Syed (Eds.), The Oxford Handbook of Identity Development (pp. 65 - 80). New York: Oxford University Press.

Kroger, J., \& Marcia, J. E. (2011). The identity statuses: Origins, meanings, and interpretations. In S. H. Schwartz, K. Luyckx, \& V. L. Vignoles (Eds.), Handbook of idenitity. Theory and research (Vol. 1, pp. 31-53). New York, NY: Springer.

Kroger, J., Martinussen, M., \& Marcia, J. E. (2010). Identity status change during adolescence and young adulthood: A meta-analysis. Journal of Adolescence, 33(5), 683-698. doi:http://dx.doi.org/10.1016/j.adolescence.2009.11.002

Kvale, S. (1996). Interviews: An introduction to qualitative research interviewing. London: Sage.

Liebkind, K. (1993). Self-reported ethnic identity, depression and anxiety among young vietnamese refugees and their parents. Journal of Refugee Studies, 6(1), 25-39. doi:10.1093/jrs/6.1.25

Marcia, J. E. (1980). Identity in adolescence. In J. Adelson (Ed.), Handbook of Adolescent Psychology (pp. 159-187). New York: John Wiley \& Sons.

Marcia, J. E., Waterman, A. S., Matteson, D. R., Archer, S. L., \& Orlofsky, J. L. (1993). Ego Identity: A Handbook for Psychosocial Research (1st ed.). New York, NY: Springer Verlag.

Meeus, W., Iedema, J., Helsen, M., \& Vollebergh, W. (1999). Patterns of Adolescent Identity Development: Review of Literature and Longitudinal Analysis. Developmental Review, 19(4), 419-461. doi:http://dx.doi.org/10.1006/drev.1999.0483 
Meeus, W., Oosterwegel, A., \& Vollebergh, W. (2002). Parental and peer attachment and identity development in adolescence. Journal of Adolescence, 25(1), 93-106. doi:http://dx.doi.org/10.1006/jado.2001.0451

Mossakowski, K. N. (2003). Coping with Perceived Discrimination: Does Ethnic Identity Protect Mental Health? Journal of Health and Social Behavior, 44(3), 318-331. doi:10.2307/1519782

Munro, G., \& Adams, G. R. (1977). Ego-identity formation in college students and working youth. Developmental Psychology, 13(5), 523-524. doi:10.1037/0012-1649.13.5.523

Nadeem, E., \& Ringle, V. A. (2016). De-adoption of an Evidence-Based Trauma Intervention in Schools: A Retrospective Report from an Urban School District. School Mental Health, 8(1), 132-143. doi:10.1007/s12310-016-9179-y

Nurmi, J.-E., Poole, M. E., \& Kalakoski, V. (1996). Age differences in adolescent identity exploration and commitment in urban and rural environments. Journal of Adolescence, 19(5), 443-452. doi:http://dx.doi.org/10.1006/jado.1996.0042

Oien, C. (2010). Underveis - En studie av enslige mindreårige asylsøkere [On the way - A study of unaccompanied minor asylum seekers] (20). Retrieved from Oslo:

Ong, A. D., Phinney, J. S., \& Dennis, J. (2006). Competence under challenge: Exploring the protective influence of parental support and ethnic identity in Latino college students. Journal of Adolescence, 29(6), 961-979. doi:http://dx.doi.org/10.1016/j.adolescence.2006.04.010

Oppedal, B., \& Idsoe, T. (2011). Gender and Cultural Equivalence of the Factor Structure of CES-D. Manuscript in preparation. Division of Mental Health, Norwegian Institute of Public Health, Oslo, Norway. 
Oppedal, B., \& Idsoe, T. (2015). The role of social support in the acculturation and mental health of unaccompanied minor asylum seekers. Scandinavian Journal of Psychology, 56(2), 203-211. doi:10.1111/sjop.12194

Oppedal, B., Keles, S., Chea, C., \& Roysamb, E. (2016). The Youth Culture Competence Scale.

A Cross-Cultural Validation of Factor Structure and Association With Depression. Manuscript Submitted For Publication.

Oppedal, B., Seglem, K. B., \& Jensen, L. (2009). Avhengig og selvstendig. Enslige mindreåriges stemmer i tall og tale. (Dependent and autonomous. The voices of unaccompanied refugees in numbers and words) (FHI-Rapport 2009:11). Retrieved from Oslo:

http://www.fhi.no/eway/default.aspx?pid=239\&trg=Content_6465\&Main_6157=6261 $\underline{: 0: 25,6740 \& \text { Content_6465=6259:82116::0:6269:2:::0:0 }}$

Perrin, S., Meiser-Stedman, R., \& Smith, P. (2005). The Children's Revised Impact of Event Scale (CRIES): Validity as a Screening Instrument for PTSD. Behavioural and Cognitive Psychotherapy, 33(04), 487-498. doi:doi:10.1017/S1352465805002419

Phinney, J. S. (1989a). Stages of ethnic identity development in minority group adolescents. Journal of Early Adolecents, 9, 34-49. doi:10.1177/0272431689091004

Phinney, J. S. (1989b). Stages of Ethnic Identity Development in Minority Group Adolescents. The Journal of Early Adolescence, 9(1-2), 34-49. doi:10.1177/0272431689091004

Phinney, J. S. (1992). The Multigroup Ethnic Identity Measure: A New Scale for Use with Diverse Groups. Journal of Adolescent Research, 7(2), 156-176. doi:10.1177/074355489272003 
Porte, Z., \& Torney-Purta, J. (1987). Depression and academic achievement among Indochinese refugee unaccompanied minors in ethnic and nonethnic placements. Am J Orthopsychiatry, 57(4), 536-547.

Pretorius, T. B. (1991). Cross-cultural application of the Center for Epidemiological Studies Depression Scale: a study of black South African students. Psychol Rep, 69(3 Pt 2), 1179-1185. doi:10.2466/pr0.1991.69.3f.1179

Radloff, L. S. (1991). The use of the Center for Epidemiological Studies Depression Scale in adolescents and young adults. Journal of Youth and Adolescence, 20(2), 149 - 166.

Roberts, R. E., Lewinsohn, P. M., \& Seeley, J. R. (1991). Screening for adolescent depression: A comparison of depression scales. Journal of the American Academy of Child and Adolescent Psychiatry, 30(1), 58-66.

Salikutluk, Z. (2016). Why Do Immigrant Students Aim High? Explaining the AspirationAchievement Paradox of Immigrants in Germany. European Sociological Review. doi:10.1093/esr/jcw004

Samuolis, J., Layburn, K., \& Schiaffino, K. M. (2001). Identity Development and Attachment to Parents in College Students. Journal of Youth and Adolescence, 30(3), 373-384. doi:10.1023/a:1010448313516

Schwartz, S. J., Côté, J. E., \& Arnett, J. J. (2005). Identity and Agency in Emerging Adulthood: Two Developmental Routes in the Individualization Process. Youth \& Society, 37(2), 201-229. doi:10.1177/0044118x05275965

Shakya, Y. B., Guruge, S., Hynie, M., Akbari, A., Malik, M., Htoo, S., . . Alley, S. (2010). Aspirations for Higher Education among Newcomer Refugee Youth in Toronto: Expectations, Challenges, and Strategies. Refuge, 27(2), $65-78$ 
Skorikov, V. B., \& Vondracek, F. W. (2011). Occupational identity. In S. H. Schwartz, K. Luyckx, \& V. L. Vignoles (Eds.), Handbook of identity theory and resaerch (Vol. 2, pp. 693 - 714 ). New York: Springer Verlag.

St-Hilaire, A. (2002). The Social Adaptation of Children of Mexican Immigrants:

Educational Aspirations Beyond Junior High School. Social Science Quarterly, 83(4), 1026-1043. doi:10.1111/1540-6237.00131

Stevenson, J., \& Willott, J. (2007). The aspiration and access to higher education of teenage refugees in the UK. Compare: A Journal of Comparative and International Education, 37(5), 671-687. doi:10.1080/03057920701582624

Tartakovsky, E. (2009). Cultural identities of adolescent immigrants: a three-year longitudinal study including the pre-migration period. J Youth Adolesc, 38(5), 654-671. doi:10.1007/s10964-008-9370-z

Teney, C., Devleeshouwer, P., \& Hanquinet, L. (2013). Educational aspirations among ethnic minority youth in Brussels: Does the perception of ethnic discrimination in the labour market matter? A mixed-method approach. Ethnicities, 13(5), 584-606. doi:10.1177/1468796812472009

Umaña-Taylor, A. J., \& Updegraff, K. A. (2007). Latino adolescents' mental health: Exploring the interrelations among discrimination, ethnic identity, cultural orientation, self-esteem, and depressive symptoms. Journal of Adolescence, 30(4), 549-567. doi:http://dx.doi.org/10.1016/j.adolescence.2006.08.002

van Doeselaar, L., Meeus, W., Koot, H. M., \& Branje, S. (2016). The role of best friends in educational identity formation in adolescence. Journal of Adolescence, 47, 28-37. doi:http://dx.doi.org/10.1016/j.adolescence.2015.12.002 
Wei-Cheng, M., \& Lynette Heim, B. (2000). Educational and vocational aspirations of minority and female students: A longitudinal study. Journal of Counseling and Development : JCD, 78(2), 186-194.

Wiley, R. E., \& Berman, S. L. (2012). The relationships among caregiver and adolescent identity status, identity distress and psychological adjustment. Journal of Adolescence, 35(5), 1203-1213. doi:http://dx.doi.org/10.1016/j.adolescence.2012.04.001

Wong, C. A., Eccles, J. S., \& Sameroff, A. (2003). The Influence of Ethnic Discrimination and Ethnic Identification on African American Adolescents' School and Socioemotional Adjustment. Journal of Personality, 71(6), 1197-1232. doi:10.1111/1467-6494.7106012

Yates, S., \& Payne, M. (2006). Not so NEET? A Critique of the Use of 'NEET' in Setting Targets for Interventions with Young People. Journal of Youth Studies, 9(3), 329-344. doi:10.1080/13676260600805671

Yoder, A. E. (2000). Barriers to ego identity status formation: a contextual qualification of Marcia's identity status paradigm. Journal of Adolescence, 23(1), 95-106. doi:http://dx.doi.org/10.1006/jado.1999.0298 
Table 1

Mean (SD) and correlations of Phase 1 measures. $N=918$

\begin{tabular}{|c|c|c|c|c|c|c|c|c|c|c|}
\hline & $\begin{array}{l}\text { Mean } \\
\text { (SD) }\end{array}$ & 1. & 2. & 3. & 4. & 5. & 6. & 7. & 8. & 9. \\
\hline 1. Aspirations & $1.47(1.06)$ & & & & & & & & & \\
\hline 2. Gender & $82 \%$ boys & $.13 * * *$ & & & & & & & & \\
\hline 3. Age & $18.61(2.61)$ & -.04 & -.03 & & & & & & & \\
\hline 4. Stay & $3.42(2.27)$ & -.04 & .05 & $.78 * * *$ & & & & & & \\
\hline 5. Depression & $20.89(9.49)$ & $-.08 *$ & $.08 *$ & -.06 & $-.13 * * *$ & & & & & \\
\hline 6. PTSD & $21.14(8.43)$ & $.11 *$ & $.09 *$ & .02 & -.01 & $.29 * * *$ & & & & \\
\hline 7. Trauma & $4.12(2.00)$ & -.003 & $-.17 * * *$ & $.12 * *$ & .05 & $.10 *$ & $.19 * *$ & & & \\
\hline 8. Discrimination & $1.80(.67)$ & $.06 *$ & -.05 & .07 & .02 & $.25 * * *$ & $.14 * *$ & $.15^{* *}$ & & \\
\hline 9. Host CC & $2.69(.60)$ & $.09 *$ & $-.10 * *$ & .05 & $.16 * * *$ & $-.25 * * *$ & $-.11 * *$ & .01 & $-.16 * * *$ & \\
\hline
\end{tabular}

Note. ${ }^{*} \mathrm{p}<.05 ; * * \mathrm{p}<.01 ; * * * \mathrm{p}<.001$; Depression and PTSD: symptoms of depression and PTSD; Host CC: host culture competence 
Table 2

ISI-ratings, background information and educational situation of the participants in Phase 2

\begin{tabular}{|c|c|c|c|c|c|c|}
\hline ISI \# & ISI Rating & $\begin{array}{l}\text { Gender, } \\
\text { Age }\end{array}$ & $\begin{array}{l}\text { Years of } \\
\text { Residence }\end{array}$ & Educational Level & Subject & Job \\
\hline 1. & $\mathrm{~A}$ & Male, 22 & 9 & College & Accounting & Part-time \\
\hline 2. & $\mathrm{~F}$ & Male, 23 & 7 & US_3voc & Plumbing* & Part-time \\
\hline 3. & A & Male, 19 & 3 & US_1voc & Construction & No, plays music \\
\hline 4. & A & Male, 19 & 7 & US_4voc apprentice & Automation & \\
\hline 5. & M & Male, 20 & 4 & US_theor & Science & \\
\hline 6. & A & Male, 22 & 8 & $\begin{array}{l}\text { Graduated from } \\
\text { US_voc }\end{array}$ & Sheet metal worker & Full time \\
\hline 7. & A & Male, 22 & 5 & Pre-college courses & Electro of renewable energy & \\
\hline 8. & M & Male, 19 & 3.5 & LS_10 & $\begin{array}{l}\text { Health and Social Sciences } \\
\text { in UL_voc next year }\end{array}$ & Part-time \\
\hline 9. & $\mathrm{~F}$ & Male, 21 & 4 & US_1voc & Constuction / Glazier & Part-time \\
\hline 10. & A & Male, 20 & 4 & US_2voc & Construction & Part-time \\
\hline
\end{tabular}




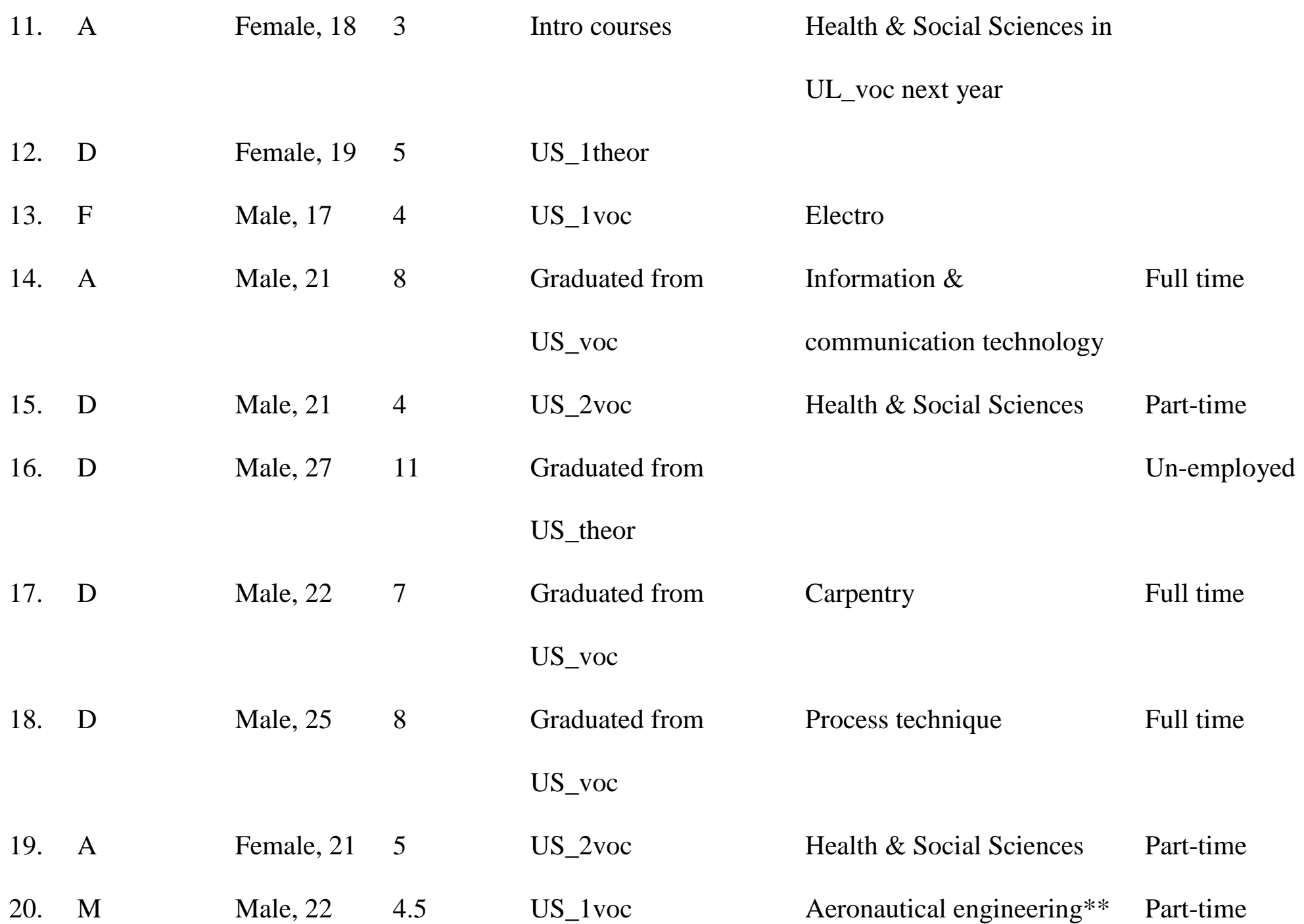


Male, $21 \quad 4$

Quit school after LS.

Probably car mechanics, but

Two part-time jobs

Plans to go back to US not yet decided

22. A

Male, 21

US_1voc

Construction

Part-time

23. $\mathrm{F}$

Male, 21

US_2voc

Construction

24. A

Female, $21 \quad 3.4$

US_2voc

Health \& Social Sciences

Part-time

25. $\mathrm{M}$

Male, 18

2.5

Intro courses. US next

Not yet decided

year

26. $\mathrm{F}$

Male, 192

LS_10.

US_theor next year

27. $\mathrm{F}$

Male, 18

2.5

US_1theor

Part-time

28. A

Male, 26

US_1voc

Restaurant \& Cooking

Part-time

29. A

Male, $22 \quad 6$

US_3voc. Apprentice. Health \& Social Sciences

Part-time

Evening courses to

fulfill US_3theor 
Note: A: Achieved; M: Moratorium; F: Foreclosed; D: Diffused; US_1voc: Upper secondary school, $1^{\text {st }}$ year vocational tracks; US_2theor:

Upper secondary school, $2^{\text {nd }}$ year theoretical tracks; LS_20: Lower secondary school, $10^{\text {th }}$ grade; Intro courses: Introductory courses of Norwegian language and social sciences for immigrants; *: he could not find apprenticeship, therefore plans to attend a vocational track of high school; **: 13 years of education pre-migration 